\title{
Conceptual Design Study of a High-Altitude Mountain Rescue Rotorcraft
}

\author{
Jonathan LAKKIS ${ }^{1}$ and Cees BIL \\ School of Engineering, RMIT University, Melbourne, Australia
}

\begin{abstract}
While there is a market for trekkers venturing into isolated environments, there will also be a market for specialized vehicles to rescue trekkers waylaid by unfortunate circumstance. This paper presents a conceptual design study of a helicopter specifically for rescue operations in extremely high altitude and mountainous terrain. Mt. Everest suffers from overcrowding and a high fluctuation of inexperienced climbers who pose a risk to themselves and other climbers around them. Rescue by fellow climbers when incapacitated is risky and difficult. There is a need for a rescue helicopter capable of hovering and extracting climbers as high up as the summit. However, there are many challenges from multiple disciplines that limit potential solutions. Helicopter sizing, economics, medical treatment, and socio-legislative policies all impact the major decisionmaking processes. This paper proposes a design that best addresses these issues using currently available technology. Turboshaft engines, contrary to electric motors, loose power with increasing altitude which means that for high-altitude operations it must be overpowered. The novelty of this design concept is the application of a compact coaxial helicopter with a hybrid-electric turboshaft propulsion system which balances the power required in high-altitude hover and cruise. The feasibility of this design is then compared to a traditional helicopter using a theoretically sized turboshaft engine. Many components from the Airbus H135 are integrated to reduce cost.
\end{abstract}

Keywords. High mountain rescue, rotorcraft, helicopter design, hybrid propulsion, transdisciplinary engineering

\section{Introduction}

Scaling Mt. Everest is one of the greatest challenges humankind can accomplish. Even though climbing equipment has significantly improved and most hazards are removed, many climbers are still unable to complete the journey. This is due to the shift in experience; since the climb has become commercialized, inexperienced climbers are flocking to the mountain in large numbers [1]. A bottleneck caused from inexperienced climbers can be seen in Figure 1. Although legislative action has been taken to reduce the number of unfit climbers, the Nepalese economy relies heavily on the revenue generated from these tourist expeditions. The safety of all those scaling Everest will continue to be at risk until a new search and rescue (SAR) platform is designed for climbers who are lost, fatigued, or incapacitated.

\footnotetext{
${ }^{1}$ Corresponding Author, Mail: cees.bil@rmit.edu.au.
} 


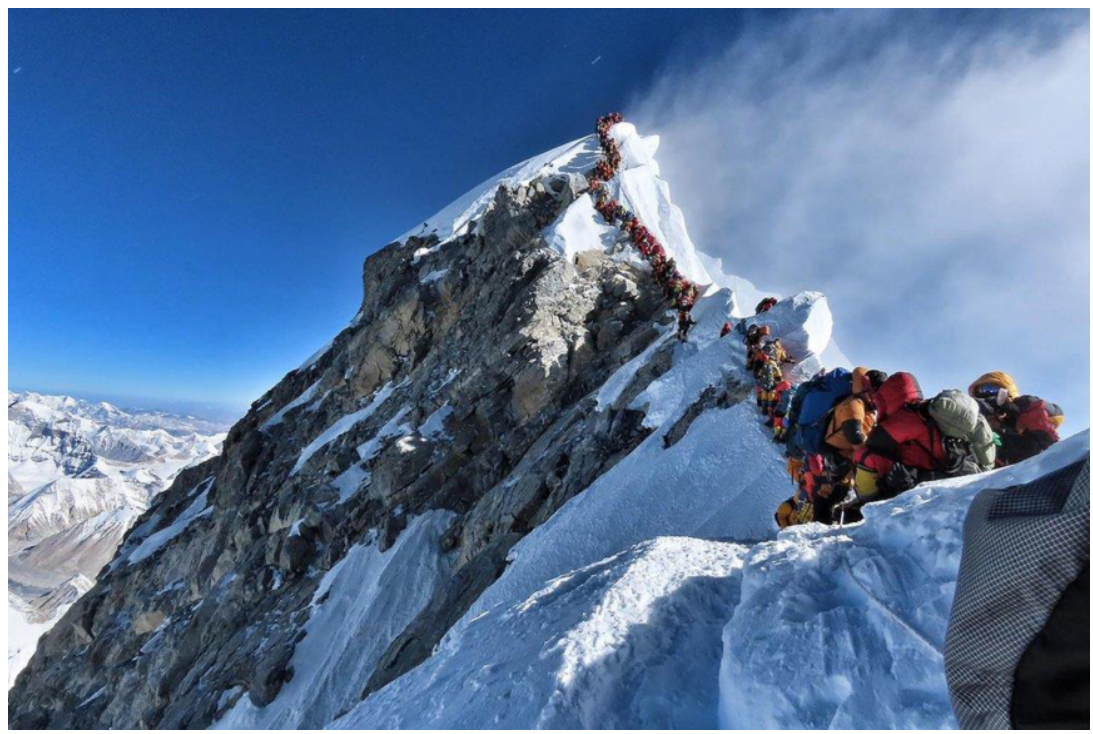

Figure 1. Bottleneck at the peak of Mt. Everest [1].

Extraction at the peak of Mt. Everest is an niche mission. In 2005, helicopter test pilot Didier Delsalle made a 3-min touch down on the top of Mt. Everest using an Airbus AS350 Squirrel B3 with 2 Arriel 2D turboshaft engines at $700 \mathrm{~kW}$ each. The helicopter was lightened for this attempt and had only the pilot onboard. Although current helicopters might reach the peak by shedding excess weight and using updrafts to their advantage, no helicopter can sustain a hover necessary for high-altitude recovery. Considering the effects of the operational environment and requirements, a top-down design process was adopted. The design requirements are summarised as:

1. Must complete the prescribed mission profile within 3 hours.

2. Must be capable of extracting injured or unconscious climbers.

3. Must include a hoist system rated for $300 \mathrm{~kg}$.

4. Must include systems capable of surveying the ground and locating the climber.

5. Must be capable of maintaining heading in winds up to $74 \mathrm{~km} / \mathrm{h}$ from any direction.

6. Shall adhere to all FAA regulations and be certified for day and night IFR flight.

7. All crew members must be capable of communicating with each other at all times.

The concept of operations (CONOPS) and performance details of the final design are presented in Figure 2. The CONOPS is representative of the infrastructure currently available for high-altitude mounteneer recovery in Nepal. Current SAR practices and medical treatment for common mountaineering distress are expanded in Section 1. Rotor selection and propulsion selection are discussed in Section 2. The performance and feasibility of the complete design are covered in Section 3.

The sizing methodology is based on Prouty [2], with additional corrections based on updated empirical data. This methodology requires an initial weight estimate determined from similar helicopters. An analytical evaluation of current platforms based on design requirements determined our concept should have a maximum take-off weight (MTOW) similar to the HAL Light Utility Helicopter, the AugustaWestland AW109, Bell 407, Airbus H135, and Kamov Ka-226. Through iteration, the final MTOW was estimated to be $2741.5 \mathrm{~kg}$ (Sea Level @ ISA $+20^{\circ} \mathrm{C}$ ). 


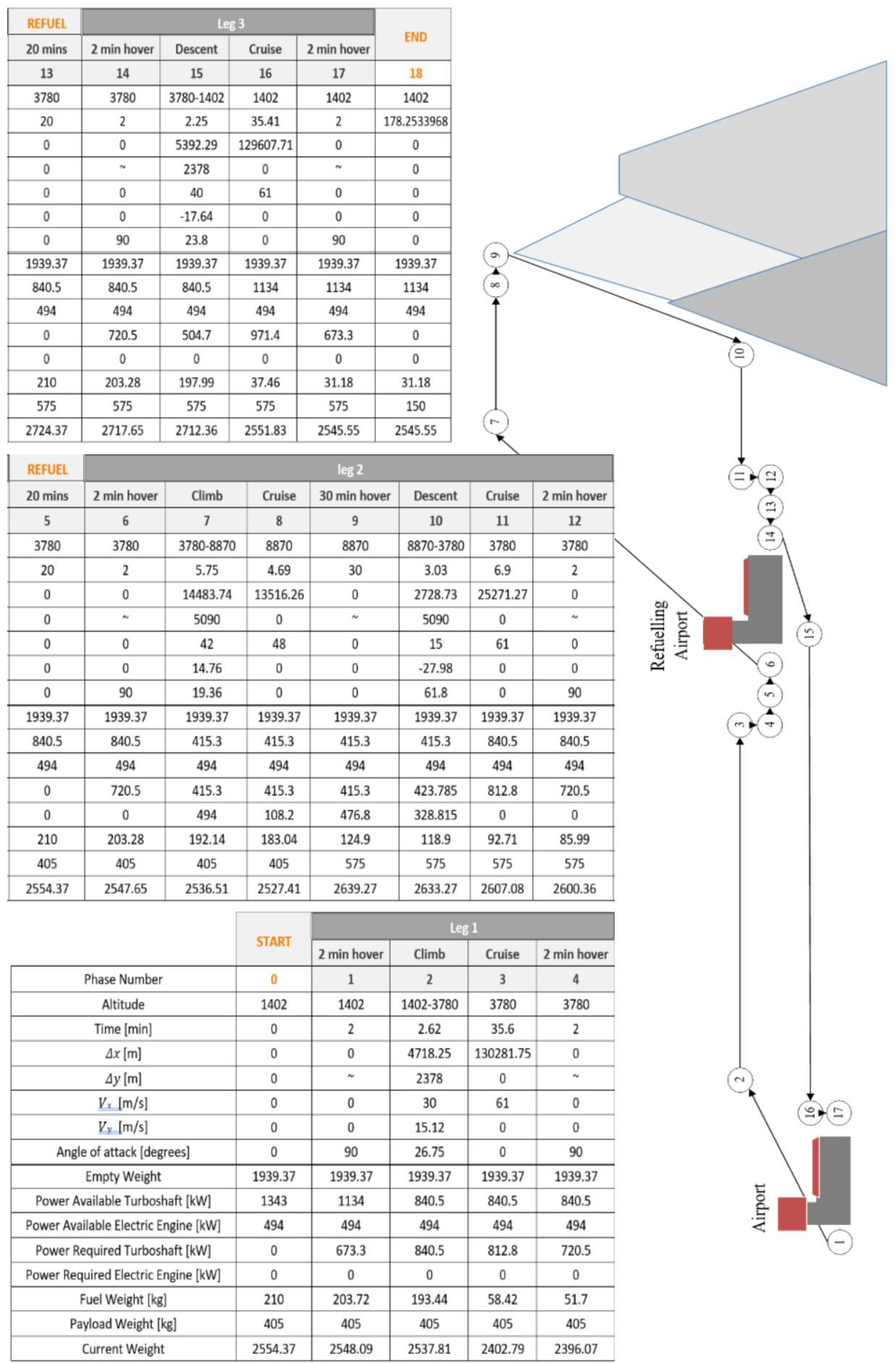

Figure 2. Mission Profile and Flight Path. 


\section{Operational Procedures}

A common misconception of search and rescue operations is that patients are treated on site. However, this is not the case since most search and rescue operations occur in conditions considered too hazardous for medical treatment. Instead, operators follow a three-step rescue procedure: Identify, Diagnose, and Stabilize. Each step has a highly detailed explanation justifying each action; however, only a few items are discussed for the sake of brevity.

Identification relates to locating the distressed patient and reviewing the surrounding area to determine the best extraction method. The safest extraction method is a ground-based extraction, where crew members are dropped off close to the distressed patient, where they are then brought to a helicopter rendezvous point. Although the CONOPS assumes a long-winch extraction at the peak, the design focus for this concept prioritizes ground-based extraction for use in other mountain search and rescue operations. Other considerations specific to Mt. Everest are whiteout, where powdered snow impairs visibility and introduced unwanted moisture in the propulsion system. A Forward Looking Infrared (FLIR) camera and search light are included as critical mission systems.

Diagnosis follows a rigorous flowchart of assessments needed to identify what trauma the patient is undergoing. A detailed breakdown of these assessments can be found in any SAR or medical response procedure guide. For mountaineering, trauma is commonly presented as a physical injury or altitude-sickness related. Both traumas can result in unconsciousness, which is considered a worst-case scenario since diagnosis becomes increasingly difficult. The patient must be rushed to a medical facility to receive a more in-depth diagnosis.

Stabilization relates to monitoring the patient's vitals until they are admitted into a medical facility. The helicopter must store a large selection of first-aid supplies, including drugs, bandages and braces, and intubation equipment. However, since space is limited, priority should be given to common trauma specific to the CONOPS. Priority treatment for altitude-related trauma is supplemental oxygen and exposure to sea level pressure. A barometric pressure chamber was considered as a critical mission system. However, it was later replaced with supplemental oxygen and rapid descent to lower altitudes since the chamber hindered access around the cabin.

Keeping in mind the SAR operational procedures during the sizing process ensures the concept has retained all critical elements necessary for practical use. Many compromises were made to reduce the weight as much as possible due to how difficult sizing became.

\section{Sizing}

Altitude density is the dominant factor for all sizing decisions. Decreased air density affects the helicopter by 1) lowering the total thrust produced by the rotors and 2) lowering the maximum continuous thrust and increasing the thrust-specific fuel consumption (TSFC) of conventional turboshaft engines.

The first sizing issue is especially important for the anti-torque rotor. Johnson's research documents that conventional tails become less efficient anti-torque devices with higher altitudes and require considerable sizing to overcome this issue [3]. To avoid this problem, dual rotor configurations with a zero-net torque or configurations 
with unconventional anti-torque control such as the NOTAR were considered. Intermeshing rotors were not considered due to blade clearance over the main cabin doors. Even if sizing the rotors for sufficient clearance, there is an unnecessary psychological hesitancy when operating near rotors angled downwards and conflicts with SAR procedure.

Four rotor configurations were considered: Tandem, Transverse, Coaxial, and NOTAR. Figure 3 shows the results of the rotor configuration trade study with weighting factors selected. Data were sourced from Jane's, so proven configurations were chosen [4]. The parameter weights prioritize hover characteristics since this is the most critical design requirement. $17.5 \%$ weighting factor was given to hover ceiling and hover stability. Other parameters considered include vibration, weight, and performance characteristics.

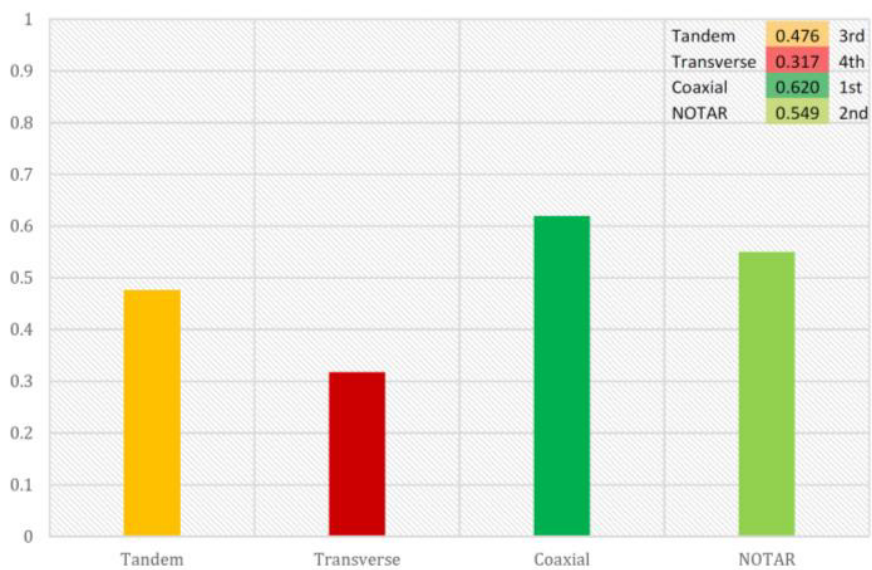

Figure 3. Rotor type selection.
Weighting factors used:

Weight $\quad 8 \%$

Useful load $\quad 5 \%$

Range $\quad 7.5 \%$

Endurance $\quad 6.25 \%$

Cruise Speed@SL 5\%

Cruise Speed@alt 0.5\%

Hover ceiling $\quad 17.5 \%$

Hover stability $\quad 17.5 \%$

Vibration $\quad 15 \%$

Year of production $\quad 6.25 \%$

Number of aircraft $\quad 4 \%$

Cost $\quad 7.5 \%$

Prioritizing hover, coaxial rotors present the best choice for the given mission profile $[5,6]$. Nonetheless, the other configurations were still investigated independently. After evaluating rotor configurations, the design team split into two subgroups for sizing the helicopter. The first subgroup focused on the coaxial rotor design, while the second subgroup sized their design using the same requirements but for tandem and transverse rotors. Investigation for the NOTAR configuration ended quickly since further research into the concept showed it was also heavily density dependant.

The tandem and transverse rotor sizing confirmed the choice for using coaxial rotors. The primary issue with these configurations was the structural weight penalty needed to support both rotors. Additionally, when sizing the fuselage, it became apparent that having a cabin stretching the length of the rotor support structure was more desirable but did not address specific design requirements and was therefore unnecessary.

The second sizing issue led to the development of two propulsion packages. For hover at the summit, the required power output for a $2,800 \mathrm{~kg}$ helicopter is about 920 $\mathrm{kW}$. For pure turboshaft configurations, this scales up to roughly $3000 \mathrm{~kW}$ of power available at sea level with a power loss of $69 \%$ at altitude. 2 Safran RTM 322 turboshafts were used in the traditional sizing approach.

Instead of sizing large and powerful turboshafts, a hybrid package incorporating lighter engines combined with electric engines can be used. 2 Safran Arriel 2N 
turboshafts, as well as 2 Siemens SP260D electric motors, are used in the hybrid sizing approach. Although the hybrid propulsion system has an increased empty weight due to the significant battery weight, it will reduce the overall fuel weight since electric propulsion does not suffer any altitude losses. A diagram of the hybrid propulsion system is shown in Figure 4.

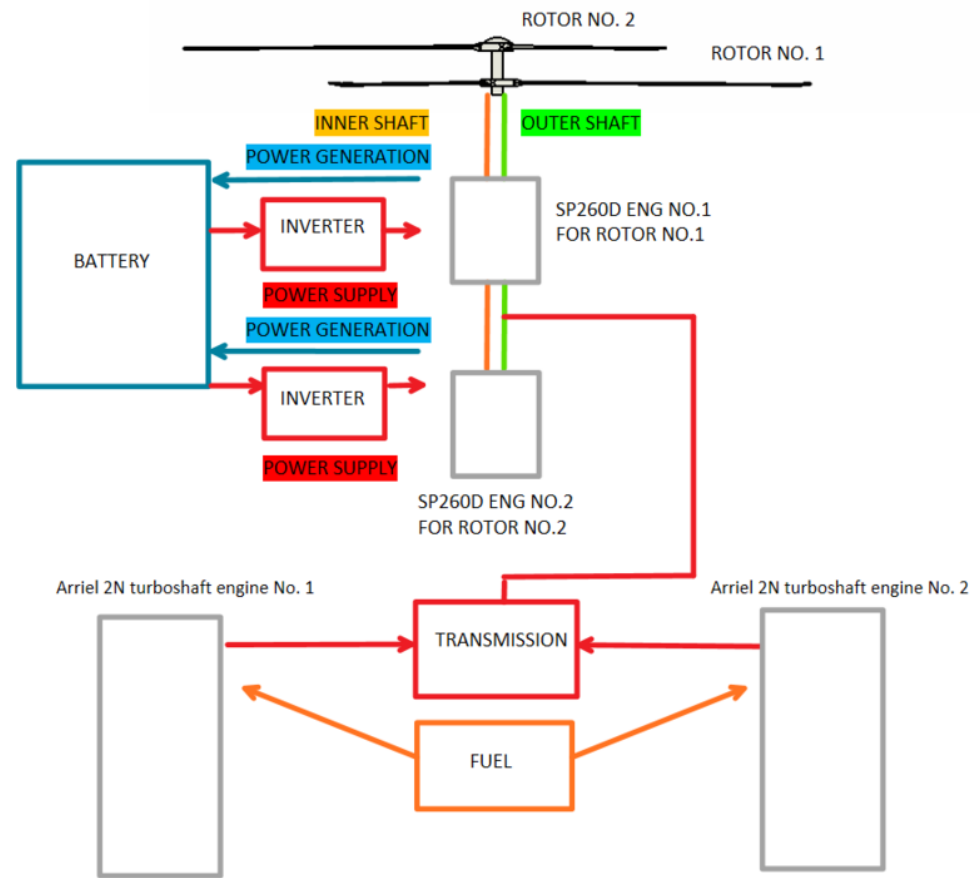

Figure 4. Hybrid propulsion system configuration diagram.

For the electric engines, the SP260D was selected since it was the only suitable electric engine currently available with the required power output. Although not in service yet, legacy models have already been implemented in small fixed-wing aircraft such as the LE300. The engine has a current TRL of 8 . More information about the SP260D is shown in Table 1 . A battery margin of $10 \%$ has been incorporated during sizing.

Table 1. Electric powerplant specifications.

2 Siemens SP260D Electric Engines Manganese-Titanium (Lithium) Battery

\begin{tabular}{|l|c|l|c|}
\hline Engine Weight & $100 \mathrm{~kg}$ & Battery Weight & $150 \mathrm{~kg}$ \\
\hline Power Output (ideal) & $520 \mathrm{~kW}$ & Specific Energy & $140 \mathrm{Wh} / \mathrm{kg}$ \\
\hline Motor Efficiency & $95 \%$ & Battery Energy & $75.6 \mathrm{MJ}$ \\
\hline Power Output (real) & $494 \mathrm{~kW}$ & Battery Volume & $0.11 \mathrm{~m}^{3}$ \\
\hline Maximum RPM & 2500 & Minimum Temperature & $-20^{\circ} \mathrm{C}$ \\
\hline
\end{tabular}

Battery technology is expected to improve in performance and affordability within the next few years. The design uses a Manganese-Titanium rechargeable battery. This battery is expensive but has a high specific energy. There is also a minimum operating 
temperature requirement; however, this can be offset with insulation and integration with the electric de-icing system.

Additionally, batteries can complicate the readiness and availability of the helicopter due to their slow charging times. In this design, the batteries are installed near the undercarriage as an interchangeable pack, where they can be easily removed and replaced. Fully charged batteries can be installed with every landing if necessary, while the depleted batteries are charged at the offsite. Since the batteries can be easily removed, the helicopter can change to a light, turboshaft helicopter like what is currently used for search and rescue. The SP260D can also recharge batteries using excess turboshaft power in flight.

After iterating both packages' design, the hybrid propulsion package is revealed as the only feasible option. The turboshaft package quickly diverged; the power requirements increased due to increasing fuel from a high TSFC. The engine required to follow the traditional sizing approach currently does not exist. On the other hand, the hybrid package converges appropriately. At design altitude, the power loss is about $50 \%$, a $20 \%$ improvement compared to the turboshaft package.

Additionally, the drive system needed for the turboshaft package is burdensome. A gear reduction ratio of 10:1 is needed for the larger turboshaft engines instead of the 3:1 gear reduction ratio required for the turboshafts in the hybrid package. The Siemens SP260D does not require a transmission system since it can be installed directly onto the driveshaft. Having a smaller gear reduction ratio results in a smaller overall transmission and reduced aircraft vibrations which is the main discomfort for search and rescue patients.

All engine data used in the evaluation process is sourced from their respective EASA type datasheet. Engines were evaluated based on power to weight ratio, power density and required gear reduction ratio. Separate trade studies were carried out for small and large turboshafts. The last aspect of sizing is the cabin layout. The interior is designed to keep all varying loads close to the centre of gravity while maximizing available space. The internal layout is shown in Figure 5.
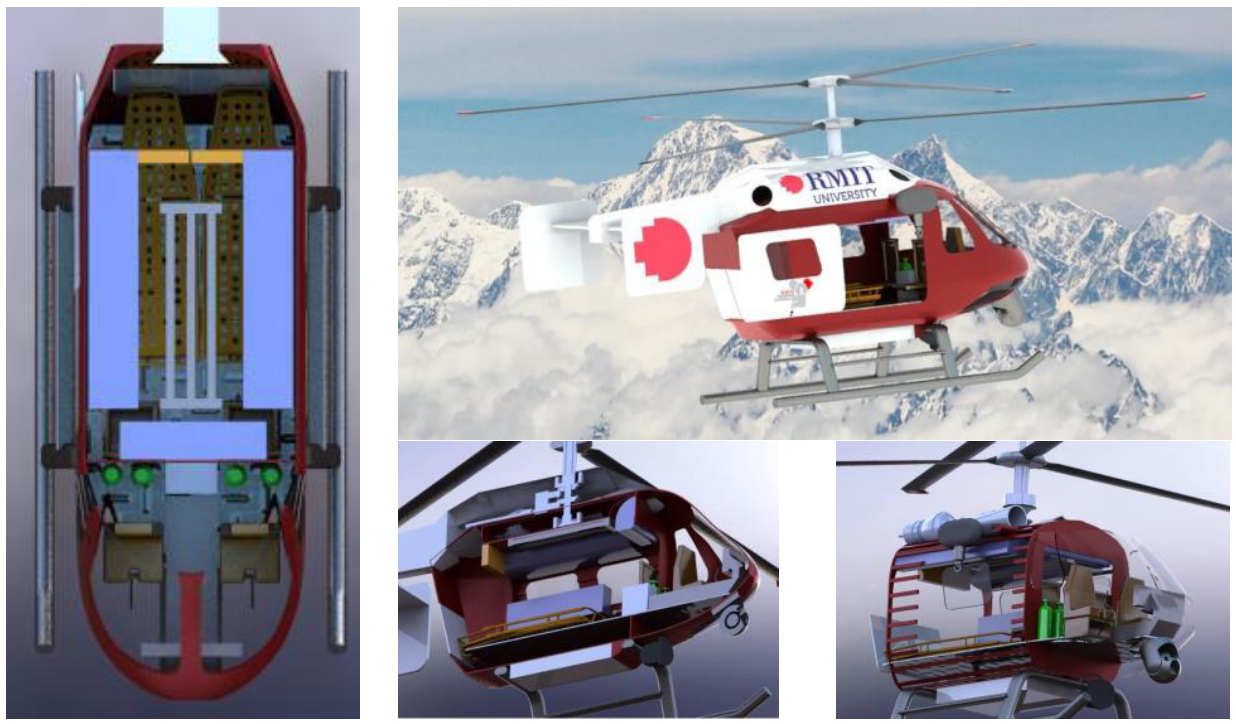

Figure 5. Final helicopter design configuration and layout. 
All subsystems and instruments are placed concerning the patient. Crew seats are positioned at the patient's head to allow for easy monitoring with fold-up seats for improved accessibility. Additional roof mounted monitors are positioned above the patient stretchers which are used to display patient vital signs or give mission information to the crew before extraction.

Clamshell doors at the back of the fuselage allow for easy egress allowing for rapid transfer from the helicopter landing site to the medical centre. Medical equipment is stored overhead by the crew members. Mountaineering equipment is stored in both the centre console and in rucksacks, which can be found behind the cabin seats alongside the supplemental oxygen tanks. The cabin must remain unpressurized since a pressurization system is too heavy and will be depressurized once the main cabin doors are open for operation. Pressurized suits were considered for the crew but, like the barometric pressure chambers, conflicted with SAR practices since they reduced mobility and limited cabin space.

\section{Performance and Feasibility}

The introduction of a hybrid propulsion system creates optional performance metrics depending on the SP260D motors required for the mission. The power available at designated altitudes is summarised in Table 2. Table 3 shows the major design and performance characteristics.

Table 2. Power available vs altitude.

\begin{tabular}{|c|c|c|c|}
\multicolumn{1}{c|}{ Altitude $(\mathrm{m})$} & Turboshaft Power $(\mathrm{kW})$ & Electric Power $(\mathrm{kW})$ & Power Available $(\mathrm{kW})$ \\
\hline Sea level & $1,342.6$ & 494 & $1,836.6$ \\
\hline 1,402 & $1,133.9$ & 494 & $1,627.9$ \\
\hline 3,780 & 840.5 & 494 & $1,334.5$ \\
\hline 8,870 & 415.3 & 494 & 909.3 \\
\hline
\end{tabular}

The power required to hover and for forward flight is derived from Prouty, with corrections made based on the statistical analysis provided by Leishman and Syal [7]. There is a minor power penalty for using coaxial rotors. The power requirements for forward flight and climb are shown in Figures 6 and 7, respectively.

Since the rate of climb depends on excess power available, the helicopter design has two possible climb charts, depending on which power sources are used. Due to the electrical engines, the rate of climb increases significantly, allowing for a much faster climb to the summit. The electrical power also makes the helicopter extremely responsive, with a maximum rate of climb of 52 $\mathrm{m} / \mathrm{s}$.

Range and endurance were approximated Table 3. Helicopter Design Summary.

\begin{tabular}{|l|r|}
\hline MTOW & $2,741 \mathrm{~kg}$ \\
\hline Empty Weight & $1,956 \mathrm{~kg}$ \\
\hline Useful load & $785 \mathrm{~kg}$ \\
\hline Max. cruise speed at SL & $273.6 \mathrm{~km} / \mathrm{h}$ \\
\hline Hover ceiling & $9,327 \mathrm{~m}$ \\
\hline Max. range at SL & $309 \mathrm{~km}$ \\
\hline Max. endurance at SL & $2.5 \mathrm{hrs}$ \\
\hline
\end{tabular}
using McCormick [8]. Power and speed for best range were approximated as power and velocity at half fuel weight. Specific fuel consumption for the Arriel $2 \mathrm{~N}$ is approximately $0.28 \mathrm{~kg} / \mathrm{kWh}$. For the proposed design, the maximum range is $309 \mathrm{~km}$ at $25 \mathrm{~m} / \mathrm{s}$ and $407 \mathrm{~kW}$, and maximum endurance is 2.5 hours at $38 \mathrm{~m} / \mathrm{s}$ and $491 \mathrm{~kW}$. The battery power provides $32.4 \%$ of the total range and 


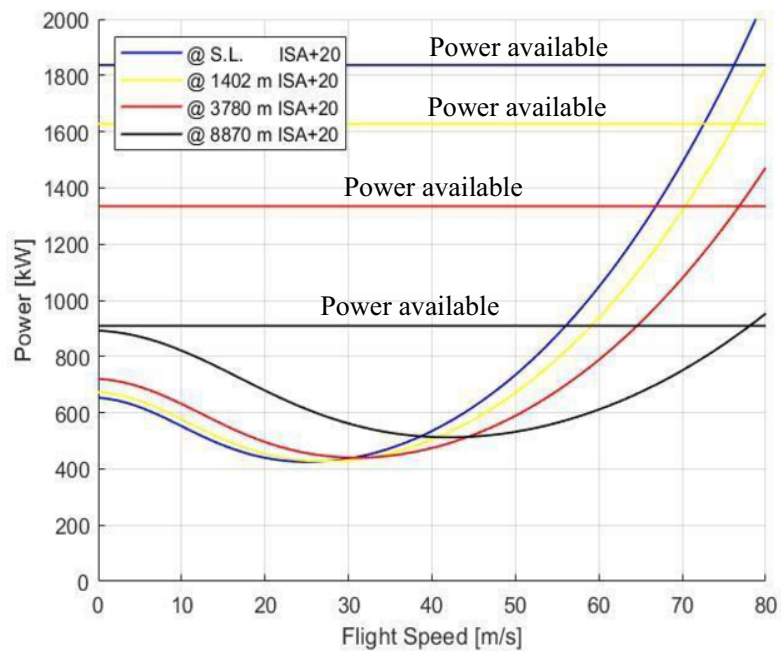

Figure 6. Power required for forward flight.

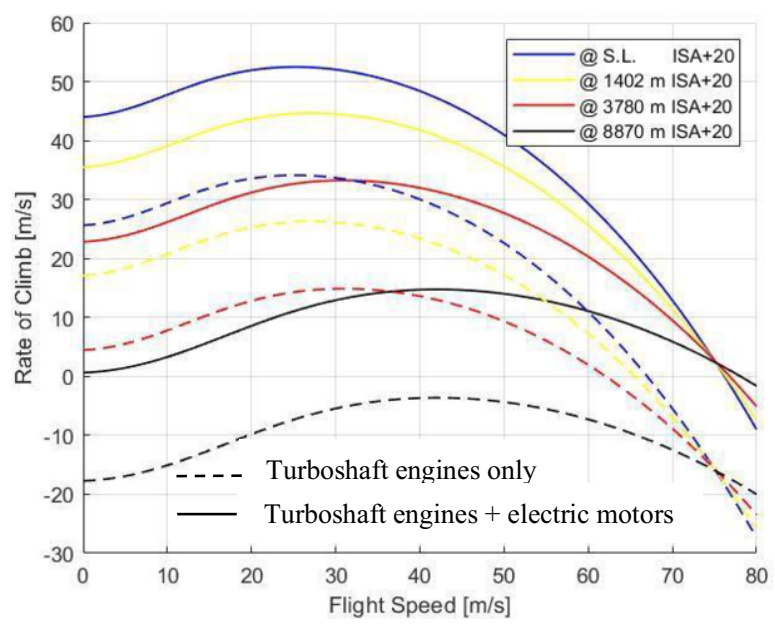

Figure 7. Maximum rate of climb vs flight speed.
$27 \%$ of the total endurance. The absolute hover ceiling for the helicopter is at 9,327 $\mathrm{m}\left(\mathrm{ISA}+20^{\circ} \mathrm{C}\right)$.

The hybrid-solution design is unlikely to be manufactured due to socioeconomic reasons. Although there is a need for high-altitude recovery, there is insufficient demand for high-altitude vehicles to justify the development costs. An cost estimate using the Johnson Space Centre Advanced Mission Cost Model (AMCM) for development costs and a cost estimate relationship function based on empirical data is shown in Table 4. To reduce development cost, the concept integrates existing components from the Airbus H135. An aircraft manufacturer might be tempted into producing this design if there were other in-demand operation at Everest-level altitudes to increase production size. In the world, there are 14 mountains higher than $8,000 \mathrm{~m} \quad$ ("eightthousanders").

Table 4. Cost breakdown vs. Manufacturer experience

\begin{tabular}{|c|c|c|c|}
\hline $\begin{array}{c}\text { Cost } \\
(\text { FY2019) }\end{array}$ & $\begin{array}{c}\text { Airbus } \\
\left(2^{\text {nd }} \text { Gen. model }\right)\end{array}$ & $\begin{array}{c}\text { Experienced } \\
\text { Manufacturer }\end{array}$ & $\begin{array}{c}\text { New } \\
\text { Manufacturer }\end{array}$ \\
\hline Development & \$327.57 Million & \$420.65 Million & \$1014.9 Million \\
\hline Unit & \$5.73 Million & \$5.73 Million & \$5.73 Million \\
\hline
\end{tabular}

Mt. Everest is only open for a few months per year seeing roughly 4 to 16 deaths per year. During the off-peak months, the design concept will have the same mission capabilities as a commercially available helicopter but with reduced range and endurance capabilities, making it an unattractive alternative. This design would be more commercially viable if engine weight and TSFC is reduced, which is likely in the next few years. Designing a greater than $3000 \mathrm{~kW}$ utility helicopter and creating a low weight variant for high-altitude recovery is more practical from an aircraft manufacturer's perspective. 


\section{Conclusion}

This paper presents a summary of a conceptual design project for a high-altitude rescue helicopter. Although some helicopters can reach the summit of Mt. Everest, sustained hovering at that extreme altitude extracting an injured mountaineer is a significant design challenge. In 2005, an Airbus EC135 B3 without payload and one pilot made a 3-min touch down on the summit of Mt. Everest. It would not have been capable of sustained hover with payload sufficent for a rescue mission.

The proposed design overcomes this problem by installing a hybrid propulsion system that consists of a combination of a turboshaft engine and electric motor. The electric motor power output is not affected by altitude and provides extra power while hovering at altitude. The hybrid concept has an advantage in hover ceiling, rate of climb, vibration, noise, and environmental pollution but has a penalty on range and endurance. The selected turboshaft engines, Arriel $2 \mathrm{~N}$, are similar to engines on the Airbus EC135 but the additional electric motors give it superior high-altitude performance. They are switched off for standard cruise operations. The likelihood of the concept being manufactured is low due to the low demand for high hover ceilings. A traditional helicopter design will likely be manufactured instead once the appropriate engine is designed with the necessary access power. Alternatively, the concept of addon electric motors can be considered to modify conventional helicopters into extremely high-altitude rescue vehicles.

\section{Acknowledgement}

This paper summarises the final design of a high-altitude rescue helicopter in response to the 2018 - 2019 VFS Student Design Competition. The RMIT University student team included: Dylan Lynch, Jonathan Lakkis, Marianne Celestial, Tharushi Bopage, Yansen Ongko and Nurul Ibrahim.

\section{References}

[1] J.G. Kai Schultz, Mujib Mashal and Bhadra Sharma, 'It Was Like a Zoo': Death on an Unruly, Overcrowded Everest, in New York Times, ed: New York Times Company, May, 262019.

[2] R.W. Prouty, Helicopter performance, stability, and control. Krieger, Malabar, Florida, 2002.

[3] W. Johnson, Helicopter theory. Courier Corporation, New Jersey, 2012.

[4] N.N., Information Handling Services Jane's all the world's aircraft. Development \& production, IHS Global Limited, Coulsdon, 2015.

[5] J. Leishman and M. Syal, Figure of Merit Definition for Coaxial Rotors, Journal of the American Helicopter Society, 2008, Vol. 53, No. 3, pp. 290-300.

[6] L.I. Garipova, A. S. Batrakov, A. N. Kusyumov, S. A. Mikhaylov, and G. Barakos, Aerodynamic and acoustic analysis of helicopter main rotor blade tips in hover, International Journal of Numerical Methods for Heat \& Fluid Flow, 2016, Vol. 26, No. 7, pp. 2101-2118.

[7] J.G. Leishman, Principles of helicopter aerodynamics, 2nd ed., Cambridge University Press, New York, 2005.

[8] B.W. McCormick, Aerodynamics, aeronautics, and flight mechanics, 2nd ed., Wiley, New York, 1995. 